\title{
Prevalence and factors associated with bullying in children attending mental health clinics: a case control study
}

\author{
Shiromi Karunaratne, Hemamali Perera, Wijini Jayawardana, Ahangamage Prabath, \\ Chandima Jeewandara
}

\section{Background}

Bullying leads to mental health problems and it is known to be more prevalent in those attending children's mental health services.

Aims

Compare the prevalence factors associated with bullying in children attending specialist mental health clinics with a group of children attending general paediatric clinics at a tertiary care children's hospital in Sri Lanka.

Methods

A working definition for a victim of bullying was identified. A descriptive analytical study was performed using a pre-tested interviewer administered questionnaire. The study population was selected from all children aged 5 to 12 years attending mental health clinics during a specified period. The control group was randomly selected during same period from children attending general paediatric clinics. Children with intellectual disability, physical disabilities and autism were excluded.
Results

The prevalence of bullying was $39 \%$ and $33 \%$ in mental health clinics and general paediatric clinics respectively. The frequency of being bullied was significantly higher in the mental health clinic sample; with $22 \%$ experiencing bullying daily compared to $14 \%$ among paediatric clinic attendees ( $p$ value $=0.031$; $\mathrm{p}<0.05)$. Behavioural problems associated with bullying, experienced by $59 \%$ in the mental health clinic sample, were significantly higher in the mental health clinic sample ( $p$ value $=0.001$ )

Conclusion

Bullying was experienced by a third of the general paediatric clinic attendees and by a significantly higher number of mental health clinic attendees in this study. A significantly higher number of children attending mental health clinics were being bullied daily. A significantly higher number of behavioural problems associated with bullying were observed among mental health clinic attendees.

SL J Psychiatry 2011; 2 (2):60-62

\section{Introduction}

Bullying in children is defined as intentional aggressive behavior that is repeated against a victim who cannot readily defend him or herself, and involves systematic abuse of power and exploitation $(1,2,3,4)$. Bullying in children is thought to be highly prevalent and its occurrence has been studied in various groups and contexts. A United States based study found that 23\% of children attending Grades 4 to 6 and $17 \%$ of children attending Grades 6 to 10 in school, experienced multiple episodes of bullying (1). Fighting associated with bullying is reported more in children in lower grades and less so with older age groups (5). Various methods of bullying are identified and broadly categorised as direct or indirect (3). Direct methods involve physical and verbal bullying; indirect methods include isolating the child and causing the child to be a victim of rumors. All bullying, irrespective of the method, is known to cause significant and sometimes long-lasting mental health problems in victims. These include hyperactivity, conduct problems and peer relationship difficulties (6). Accordingly, the experience of bullying is high among children attending mental health services (7). Some temperamental and environmental risk factors have been identified, which make children more vulnerable to bullying (8).

There are no published data available in Sri Lanka on the prevalence or related psychosocial issues in bullying in children. The objectives of this study were to estimate the prevalence and correlates of bullying in children attending specialist mental health clinics and compare them with children attending the general paediatric clinics.

\section{Method}

This descriptive analytical study was conducted at a tertiary care children hospital in Sri Lanka. . The study sample was selected from those attending specialist mental health clinics during the month of January 2011 and included all children attending as new referrals and those on follow-up visits (9). Children with intellectual disability, physical disabilities and autism were excluded to avoid any bias in bullying experience due to their specific health issues (10).

A pre-tested structured questionnaire was interviewer administered to the child and the accompanying parent with informed consent from the parent (11). The questionnaire focused on demographic data, the type of the bullying experience (using a checklist of known methods of bullying), presenting mental health problem, if any (including history, mental state and diagnosis arrived at from the clinical evaluation) and the temperamental characteristics of the child (adapted from a standard classification). For this study, the experience of bullying was defined as intentional 
negative behaviour towards the child by another child (including siblings) or a known adult (a non-family member), on more than two occasions during the previous six months, causing substantial distress to the child. It was noted whether the child who reported bullying had also acted as a bully in addition to being a victim.

The control group was randomly selected from children (new referrals and those on follow-up visits) attending general paediatric clinics during the same period. They were matched for age and sex and similar exclusion criteria were applied. Ethical clearance was obtained from the Ethical Review Committee of the hospital. The chi-square test was used to estimate the difference between groups and the level of significance was set at 0.05 .

\section{Results}

Analysis of bullying behavior in the total sample A total of 395 children participated in the study. The study sample consisted of 177 children, in the 5 to 12 year age group $($ Mean $=9$ years, Median $=9$ years $)$ and $65 \%$ (116) were male. The control group consisted of 218 children in the same age group (Mean=9years, Median $=8$ years ) and $60 \%$ (131) were male. Both the study and controls samples were similar in sociodemographic dimensions (family income, parental educational level). Children attending mixed gender schools from the study and control groups were $74 \%$ and $71 \%$ respectively.

Bullying was reported by $141(35.7 \%)$ children in the total sample. Of these, $69(39.0 \%)$ children attending mental health clinics and $72(33 \%)$ from the control group were affected. Among the total participants of the study, $69(17 \%)$ were only victims of bullying, while $62(15 \%)$ admitted to being a bully as well a victim. The total duration of the bullying experience was more than one year in $78(20 \%)$, while $21(5 \%)$ experienced bullying for 6-12 months.

Of the children who were bullied $77.3 \%$ were male and $22.7 \%$ were female. The prevalence of bullying among males was $46 \%$ and $42 \%$ respectively in the mental health and general paediatric clinic samples. The prevalence of bullying among females was $26 \%$ and $18 \%$ respectively.

The methods of bullying reported were both direct (assaulting, spitting, kicking, stealing belongings, name calling, teasing, threatening, using abusive language) and indirect (isolating the child, making false complaints against child, preventing the child from interacting with others ). Modern methods of bullying reported in recent literature, such as cyber bullying and sexual bullying was not reported. Being subjected to physical methods of bullying was reported by 100 children (25\%) compared to verbal bullying reported by 103 children (26\%), some being bullied by both methods. Isolation of the victim was experienced by $25(6 \%)$.

Of those bullied, $100(70.9 \%)$ were bullied by a classmate. Other perpetrators were older peers $20(14 \%)$,
Table 1 - Comparison of variables related to bullying between children attending mental health clinics and medical clinics

\begin{tabular}{|c|c|c|c|}
\hline & $\begin{array}{l}\text { Study } \\
\text { group }\end{array}$ & $\begin{array}{l}\text { Control } \\
\text { group }\end{array}$ & $p$ \\
\hline Gender & & & 0.266 \\
\hline Male & $53(77 \%)$ & $56(78 \%)$ & \\
\hline Female & $16(23 \%)$ & $16(22 \%)$ & \\
\hline $\begin{array}{l}\text { Frequency of bullying } \\
\text { experience }\end{array}$ & & & 0.031 \\
\hline Daily & 39 (56\%) & $30(42 \%)$ & \\
\hline >Once a week & $18(26 \%)$ & $21(29 \%)$ & \\
\hline Once a week & 06 (09\%) & $16(22 \%)$ & \\
\hline$<$ Once a week & $06(09 \%)$ & $05(07 \%)$ & \\
\hline Status regards bullying & & & 0.238 \\
\hline Victim only & $32(46 \%)$ & 37 (51\%) & \\
\hline Bully / victim & $33(48 \%)$ & 29 (40\%) & \\
\hline Observer and victim & $01(01 \%)$ & 05 (07\%) & \\
\hline $\begin{array}{l}\text { Bully observer and } \\
\text { victim }\end{array}$ & 03 (04\%) & 01 (01\%) & \\
\hline Experience of method & & & 0.106 \\
\hline Direct & $46(66 \%)$ & $59((82 \%)$ & \\
\hline Indirect & $01(01 \%)$ & 01 (01\%) & \\
\hline Both methods & $22(31 \%)$ & $12(17 \%)$ & \\
\hline Impact of bullying & & & \\
\hline Behaviour problems & $41(59 \%)$ & $21(29 \%)$ & 0.001 \\
\hline School related problems & $45(65 \%)$ & $36(50 \%)$ & 0.068 \\
\hline
\end{tabular}

siblings $17(12 \%)$ and known adults including teachers $10(7 \%)$. Bullying mostly occurred in a school setting $129(91.4 \%)$. Other settings were at home $10(7 \%)$ and in the neighbourhood. Seven percent of victims of bullying from the study sample also reported being an observer of others being bullied. None from the control group reported this behavior.

In describing the temperament of the victim of bullying, the parents identified them as timid and shy in $72 / 141(51 \%)$. Those who easily angered represented $70 / 141(50 \%)$. No temperamental difficulties were identified in $47 / 141(34 \%)$.

The victims of bullying adopted different methods in response to bullying. These included retaliation in $68(48 \%)$, avoidance of the bully in $31(21 \%)$ and complaining to parent or teacher in $9(6 \%)$ children.

\section{Comparison of bullying victims in the study and control samples}

In the 69 children from the study sample, the associated mental health problems were clinically evaluated. Behavioural problems (hyperactivity, irritability, aggressive behaviour towards others, disruptive behaviour in classroom and outbursts of anger) were elicited in $41(59 \%)$ and school related difficulties (academic underperformance, refusal to attend school) in $45(65 \%)$. In the paediatric clinic sample behavior problems related to bullying were elicited in $21(29 \%)$ and academic problems in $36(50 \%)$. Other reported problems included somatic complaints, refusal of food, bed-wetting and social withdrawal. 


\section{Discussion}

In the total sample, $35.7 \%$ of the children reported experiencing bullying. A higher proportion of mental health clinic attendees reported bullying experiences compared to paediatric clinic attendees (39\% to 33\%) although this was not statistically significant. However, the frequency of being bullied was significantly higher among mental health clinic attendees $(\mathrm{p}=0.031)$, with many $(22 \%)$ experiencing bullying daily.

Behaviour problems associated with bullying were significantly higher in the sample from the mental health clinic $(\mathrm{p}=0.001)$.

In this study, male children were more likely to get bullied with a $2: 1$ male:female risk ratio. This was compatible with the available literature (12).

As the sample studied came from both mental health and non-mental health clinic settings they can be seen as coming from the general population to some extent, even though this may not constitute a strict cross section. In that context, the prevalence rate found in this study is higher than most reported. However, there are no studies in this age group (community or clinic based) for comparison from Sri Lanka. Although the experience of bullying was higher in the study population, it is not possible to establish from the results whether their mental health problems were a cause or a consequence in relation to the bullying experience. Nevertheless, based on the findings on temperament, behavior problems and school difficulties, it is likely that both these categories of children were represented in the study group.

Other prevalence studies show that children who get bullied experience multiple forms of bullying which conforms with our findings, Comparable statistics are not available as most prevalence studies are community-based rather than clinic-based.

This study relied entirely on verbal reporting by parents and children on direct interviewing. Other studies have detected under-reporting with this method and a higher prevalence of bullying was elicited when data collection was attempted via postal questionnaires (13). Also, recall bias could not have been avoided and may have led to under-reporting. However, the questionnaire method was used in this study as this is the most favoured and frequently used in studies of a similar nature (11). In addition, data gathering being confined to the interviewing of the parent and child only may have limited the identification of adult perpetrators especially within the family.

\section{Conclusions}

The fact that about a third of children attending the non-mental health as well as the mental health settings reported bullying suggests an alarming trend and community based studies are needed to establish the prevalence of bullying among children in the general population.

\section{Declaration of interest \\ None}

\author{
Shiromi Karunaratne Registrar in Psychiatry \\ Hemamali Perera, Professor, Department of \\ Psychological Medicine, Faculty of Medicine, \\ University of Colombo, Sri Lanka \\ Wijini Jayawardana, Senior Registrar in Psychiatry \\ Ahangamage Prabath Registrar in Psychiatry \\ Chandima Jeewandara, Medical Officer in \\ Psychiatry, Lady Ridgeway Hospital for Children, \\ Colombo, Sri Lanka \\ Corresponding author \\ Shiromi Karunaratne \\ E mail: shiromikarunaratne@yahoo.com
}

\section{References}

1. What is Bullying? Definition, statistics \& Information on Bullying. Olweus bullying prevention program. Available at: http://olweus.org/public/bullying.page (Accessed: 13-Dec-2011).

2. Rigby, K. Bullying in Schools and the Mental Health of Children Australian journal of guidance and counseling 2005;15(2): 195-208.

3. Cardiff Against Bullying [homepage on the Internet]. Available at http://www.cardiff.gov.uk/content.asp?n $\mathrm{av}=2869,3047,3049,3073,5443,5450,5478 \&$ parent directory_id=2865 (accessed 14 December 2011).

4. Smith, $\mathrm{P}, \mathrm{K}$. Bullying: Recent Developments. Child and Adolescent Mental Health 2004; 9(3): 98-103. CrossRef

5. Bullying facts $\mid$ cyber bullying facts $\mid$ bully statistics | bullying stats. Available at http://www.how-tostop-bullying.com/bullyingstatistics.html (accessed December 13 2011).

6. Wolke ,D. Woods, S .Bloomfield, L. Karstadt,L .The Association between Direct and Relational Bullying and Behaviour Problems among Primary School Children J. Child Psychol. Psychiat. 2000; 41(8): 989-1002. CrossRef

7. Preventing Bullying in Schools and the Community [homepage on the Internet]. National centre for mental health promotion and youth violence prevention, USA . Available at http://www.promoteprevent.org/ publications/prevention-briefs/preventing-bullyingschools-and-community (accessed 14 November 2011).

8. Ball, H.A. Arseneault L, Taylor,A.et al .Genetic and environmental influences on victims, bullies and bullyvictims in childhood. J. Child Psychol. Psychiat. 2008; 49(1) : 104-112. CrossRef

9. Naing,L. Winn,T.Rusli,B.N .Medical Statistics-Practical Issues in Calculating the Sample Size for Prevalence Studies. Archives of Orofacial Sciences. 2006; 1: 9-14.

10. Hay, D.F. Payne, A. Chadwic,A .Peer relations in childhood. J. Child Psychol. Psychiat. 2004; 45(1): 84108. CrossRef

11. O'Moore,M .Summary of Research Methods and Tools used in relation to studying the prevalence and nature of Bullying and Violence in Schools European Commission - Education and Culture - Connect Program

12. Bullies: More Than Sticks, Stones, and Name Calling -NYU child study centre -giving children back heir childhood [homepage on the Internet]. Available at http://www.aboutourkids.org/articles/bullies_more sticks_stones_name_calling (accessed 14 November 2011).

13. Quinn,P. Bullying in schools: detection in an adolescent psychiatric clinic practice compared with questionnaire survey. Child and Adolescent Mental Health 1996; 1:139-45. CrossRef 